Authors' accepted manuscript

Paper presented at TMS 2015 144th Annual Meeting and Exhibition (Orlando, FL, USA, March 15-19, 2015)

Published in Characterization of Minerals, Metals, and Materials 2015 (Springer)

The final published version is available at https://doi.org/10.1007/978-3-319-48191-3_13

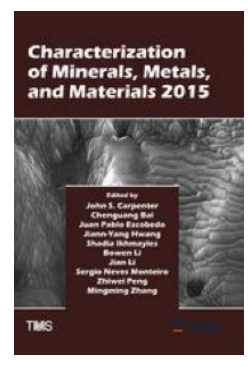

Characterization of Minerals, Metals, and Materials 2015 pp 107-114|

The Effect of Strain Reversal during High Pressure Torsion on the Microstructure Evolution and Texture of Aluminum Alloys

- Authors

- Authors and affiliations

- K. Chadha

- P.P. Bhattacharjee

- M. Jahazi

- DOI: 10.1007/978-3-319-48191-3_13 


\title{
THE EFFECT OF STRAIN REVERSAL DURING HIGH PRESSURE TORSION ON THE MICROSTRUCTURE EVOLUTION AND TEXTURE OF ALUMINUM ALLOYS
}

\author{
K.Chadha ${ }^{1}$, P.P.Bhattacharjee ${ }^{2}$, M.Jahazi ${ }^{1}$ \\ 1. Department of Mechanical Engineering, École De Technologie Superieur, Montreal \\ Qc Canada
}

2. Dept. of Materials Science and Engineering, Indian Institute of Technology, Hyderabad, Yedumaillarum, Dist. Medak, Andhra Pradesh

Keywords: Aluminum Alloys, Strain Reversal, High Pressure Torsion, Microstructural evolution, Texture.

\begin{abstract}
The present work investigated the effect of strain reversal during high pressure torsion on the evolution of microstructure, texture and hardness properties of two different materials with different dynamic recovery behavior, namely, high purity (99\%) Aluminum (2N-Al) and Aluminum-Magnesium (Al-2.5\%Mg) alloy. In the two aluminum alloys subjected to different routes, the evolution of the ultrafine structure followed same trend. At lower strain level, sub grains with prominent LAGBs network were observed and at higher strains, ultrafine equiaxed grains separated by HAGBs were observed throughout the disk. The texture evolution in monotonically and strain reversal processed $2 \mathrm{~N}-\mathrm{Al}$ and $\mathrm{Al}-2.5 \% \mathrm{Mg}$ showed presence of typical torsion texture components at different strain levels. The strength of the components was observed to follow different trends depending on the processing routes.
\end{abstract}




\section{Introduction}

Development of high strength structural materials through grain size reduction as conceived in the Hall-Petch relation $\left(\sigma_{\mathrm{Y}}=\sigma_{0}+\mathrm{kd}^{-1 / 2}\right)$ [1] has been a major driving force in the fabrication of Ultrafine Grained (UFG with grain size $<1 \mu \mathrm{m}$ ) and Nanostructured (NS with grain size $<100 \mathrm{~nm}$ ) materials with large fraction of high angle grain boundaries (HAGBs). Severe Plastic Deformation (SPD) is the most well-known approach for fabricating UFG and NS materials. SPD techniques such as Equi Channel Angular Processing (ECAP) [2], Accumulative Roll Bonding (ARB) [3] and High Pressure Torsion (HPT) [4] can now successfully produce wide variety of bulk Ultra Fined Grained and Nano structured materials.

Amongst various SPD processing techniques HPT has gained significant attention due to fact that large plastic strain value can be easily achieved in this process. The sample in the form of thin disc is placed between two anvils and a very high compressive load is applied with torsion strain.

The equivalent strain be calculated by:

\begin{tabular}{|c|c|}
\hline Component & $\{$ hkl $\}<$ uvw $>$ \\
\hline A & $\{1 \overline{1} \overline{1}\}<110>$ \\
\hline A- & $\{\overline{1} 11\}<\overline{1} \overline{1} 0>$ \\
\hline A $^{*}$ & $\{\overline{1} \overline{1} 1\}<112>$ \\
\hline A $_{-}$ & $\{11 \overline{1}\}<112>$ \\
\hline B & $\{\overline{1} 12\}<110>$ \\
\hline B- & $\{1 \overline{1} \overline{2}\}<\overline{1} \overline{1} 0>$ \\
\hline C & $\{001\}<110>$ \\
\hline
\end{tabular}
simultaneous value in HPT can

Where $r=$ radius of the height of disc in $\mathrm{mm}, \varphi=$ angle of rotation in radians and $\epsilon=$ equivalent strain value. According to the equation the strain is directly proportional to the radius of the disc which indicates that at the centre the strain is ideally zero whereas the strain is highest at the edges of the disc. Extensive research has been conducted on aluminum alloys to investigate the effect of HPT on the evolution of microstructure and mechanical properties $[5,6]$. It is generally observed that HPT processing leads to development of ultrafine grains at high strain levels separated by high angle grain boundaries (HAGBs).

In contrast, texture studies on HPT materials are rather limited and have been carried out by few researchers only [7, 8]. Torsion texture development in F.C.C. metals are expressed by $\{\mathrm{hkl}\}<\mathrm{uvw}>$ notation, where $\{\mathrm{hkl}\}$ set of planes parallel to the shear plane and $\langle\mathrm{uvw}\rangle$ is the shear direction $\Theta$. Four types of ideal orientations are observed.

Table I: Ideal texture components for fcc metals

Torsion texture evolution in $\mathrm{Al}$ and $\mathrm{Cu}$ has been studied by Montheillet et al [8]. The report discussed development of torsion texture during conventional deformation. The 
study reveals that A component $\{1 \overline{1} \overline{1}\}<110>$ dominates at lower strains whereas the $\mathrm{C}$ component $\{001\}<110>$ dominates at higher strain values. The strain path change during HPT can be easily achieved by reversal strain deformation through the combination of clockwise (CW) and subsequent anticlockwise rotation (CW-CCW). The effect of strain reversal during HPT on the evolution of hardness and microstructure has been reported by few researchers [10,11]. It has been reported by Orlov et al [11], that strain reversal retards the formation of HAGBs and thereby less grain refinement in case of $99.99 \%$ pure aluminum. Orlov et al. investigated on the development of texture during monotonic and strain reversal in high purity aluminum [9]. It is reported that there is development of A fibre in both deformation modes at lower strain levels whereas at higher strain levels, $\mathrm{C}$ component becomes the dominant in monotonic deformation and (001) [100] becomes dominant in strain reversal deformation.

It might thus be clearly pointed out that understanding the evolution of microstructure and texture of different aluminum alloys subjected to both monotonic and strain reversal deformation during HPT processing is insufficient and there are greater needs to address these issues which are the major focus of the present work.

\section{Experimental}

Commercially purity (99\%) $2 \mathrm{~N}-\mathrm{Al}$ and $\mathrm{Al}-2.5 \% \mathrm{Mg}$ alloy were used for the present study. $2 \mathrm{~N}$-Al was received in the form of fully annealed plates of approximately $2 \mathrm{~mm}$ thickness. The as-received Al-2.5\%Mg block $(160 \mathrm{~mm}($ length $) \times 60 \mathrm{~mm}$ (width) $\times$ $10 \mathrm{~mm}$ (thickness)) was cold rolled to $\sim 80 \%$ reduction in thickness and annealed in air furnace at $673 \mathrm{~K}$ for one hour. The above two materials were used as the starting materials for further procesasing. Disks with the diameter of $10 \mathrm{~mm}$ were then cut from the sheet using EDM wire cut equipment. A total of 2 disks of each alloy were cut for further HPT processing. These disks having $2.5 \mathrm{~mm}$ starting thickness were manually grinded to $\sim 1.5 \mathrm{~mm}$ thickness using $\mathrm{SiC}$ grit papers The disks were then designated according to the strain value or the number of rotations as per the given chart.

Table II: Designation of the samples according to the strain

\begin{tabular}{|c|c|c|}
\hline Monotonic & Strain Reversal & Equivalent Strain \\
\hline $\mathrm{CW} 30^{\circ}$ & $\mathrm{CW}\left(15^{\circ}\right)-\mathrm{CCW}\left(15^{\circ}\right)$ & 1 \\
\hline $\mathrm{CW} 120^{\circ}$ & $\mathrm{CW}\left(60^{\circ}\right)-\mathrm{CCW}\left(60^{\circ}\right)$ & 4 \\
\hline
\end{tabular}

$\mathrm{CW}$ - Clockwise Rotations, CW-CCW - Clockwise followed by counter clockwise

The disks were then deformed by HPT to the desired strain levels. The imposed load was fixed at $390 \mathrm{KN}(\sim 5 \mathrm{GPa})$ and a rotation speed of $1 \mathrm{rpm}$ was used at quasiconstrained conditions [15]. The processing of the disks was done at POSTECH, South Korea in the group of Prof. H.S. Kim. To measure the hardness variation across the disk, Vickers microhardness test (Make: EMCO-TEST, Austria; Model: Dura Scan-70) was conducted on the disks. The disks were mounted using Hot Mounting Equipment (Make: Struess Citupress-10) and then manually grinded and polished in order to obtain a mirror finish. The microstructure and texture of the processed HPT disks were characterized by Electron Back Scattered Diffraction (EBSD) attached to a FEG-SEM (Make: Carl Zeiss; Model Supra 40) using Channel 5 ${ }^{\mathrm{TM}}$ Software (Oxford Instruments, UK). The EBSD measurements were taken on the $r-\theta$ plane of disks at edge region. For EBSD investigations, the sample were polished mechanically using $\mathrm{SiC}$ paper of grit 
size 2000, followed by electropolishing using a mixture of perchloric acid and ethanol as electrolyte (1:9) at $20 \mathrm{~V}$ and $-30^{\circ} \mathrm{C}$ (using Liquid $\mathrm{N}_{2}$ ) for $20 \mathrm{sec}$. The microtexture analysis was done by assuming triclinic sample symmetry.

\section{Results}

\section{$\underline{\text { Microstructure Evolution }}$}

\section{Commercially Pure Aluminum (2N-Al)}

The grain boundary (GB) maps of the samples deformed by different deformation modes are shown in Figure 1. Only the edge region has been considered here as maximum strain is accumulated at the edge of the specimen because of the torsional geometry. The high angle grain boundaries HAGBs having misorientation $\left(\theta_{\text {mis }} \geq 15^{\circ}\right)$ are highlighted in black and low angle grain boundaries LAGBs with misorientation $\left(15^{\circ} \geq \theta_{\mathrm{mis}} \geq 2^{\circ}\right)$ are highlighted in red.

After $\varepsilon=1\left(\mathrm{CW} 30^{\circ}\right)$, Figure 1 (a), the microstructure consists of starting recrystallized grains but inside the starting recrystallized grains LAGBs network can be easily observed. Further deformation upto $\varepsilon=4\left(\mathrm{CW} 120^{\circ}\right)$, refines the microstructure so that equiaxed microstructure could be observed. Deformation at this level (at $\varepsilon=4\left(\mathrm{CW} \mathrm{120^{ \circ }}\right)$ results in the evolution of an ultrafine microstructure at the edge regions characterized by rather equiaxed grains separated by HAGBs. The average grain size continuously decreases at the edge as the number of rotations increases. The average grain size at the edge reduces from $\sim 3.6 \mu \mathrm{m}$ after $30^{\circ}$ clockwise rotation to $1.7 \mu \mathrm{m}$ after $120^{\circ}$ rotation. The fraction of HAGBs, at the edge increases drastically to $80 \%$ after $120^{\circ}$ clockwise rotations from $30 \%$ after $30^{\circ}$ rotation. Figs. 1 ((c) \& (d)) show the GB maps of strain reversal specimens at different strain levels. The microstructural evolution for edge regions appears very similar for both the deformation modes such that at lower strains the structure consists of huge fraction of LAGBs and with increasing strain gradually transformation into an ultrafine-grained structure could be observed. After $30^{\circ}$ clockwise-counter clockwise $\left(\mathrm{CW}\left(15^{\circ}\right)-\mathrm{CCW}\left(15^{\circ}\right)\right)$ rotation, the average grain size decreases from $\sim 28 \mu \mathrm{m}$ to $\sim 4 \mu \mathrm{m}$ in edge region. The average grain size reduces from $\sim 4 \mu \mathrm{m}$ after $30^{\circ}$ strain reversal $\left(\left(\mathrm{CW}\left(15^{\circ}\right)-\mathrm{CCW}\left(15^{\circ}\right)\right)\right)$ rotation to $1.5 \mu \mathrm{m}$ after $120^{\circ}$ strain reversal rotations $\left(\mathrm{CW}\left(60^{\circ}\right)-\mathrm{CCW}\left(60^{\circ}\right)\right)$. HAGBs fraction increases from $30 \%$ at edge region after $30^{\circ}$ strain reversal $\left(\mathrm{CW}\left(15^{\circ}\right)-\mathrm{CCW}\left(15^{\circ}\right)\right)$ to $64 \%$ after $120^{\circ}$ strain reversal $\left(\mathrm{CW}\left(60^{\circ}\right)-\mathrm{CCW}\left(60^{\circ}\right)\right)$.
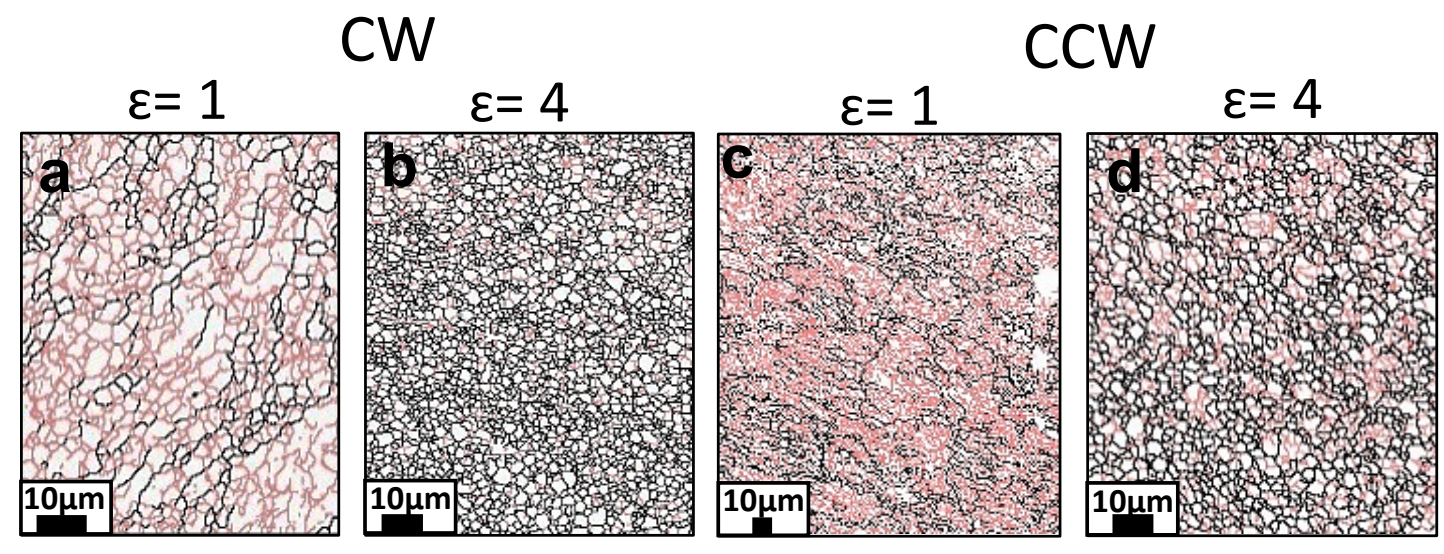
Figure 1. Grain boundary maps of $2 \mathrm{~N}-\mathrm{Al}$ clockwise rotations of monotonous deformed specimens (a \& b) and strain reversal deformed specimens (c \& d).

\section{Aluminium Magnesium Alloy (Al-2.5\%Mg)}

The grain boundary (GB) maps of the samples deformed by different deformation modes are shown in Fig 2. After $\varepsilon=1$ (Fig 2 (a)), the microstructure consists of mostly sub grains with prominent LAGB network inside the grains. At $\varepsilon=4$ a much finer structure is observed at the edge region. The average grain size at the edge reduces from $\sim 8 \mu \mathrm{m}$ after $\varepsilon=1$ to $760 \mathrm{~nm}$ after $\varepsilon=4$. The fraction of HAGBs, at strain level after $\varepsilon=1$ increases from $14 \%$ respectively to $62 \%$ after $\varepsilon=4$. Figs. 2 ((c) \& (d)) show the GB maps of strain reversal specimens at different strain levels. The microstructure evolution for edge region is similar for both deformation modes, such that at lower strains the structure consists of huge LAGBs and with increasing strain gradually transforms into an ultrafine grained structure. The average grain size decreases from 31 $\mu \mathrm{m}$ to $4 \mu \mathrm{m}$ after $\varepsilon=1$. The average grain size edge region reduces continuously from $4 \mu \mathrm{m}$, after $\varepsilon=1$ to $400 \mathrm{~nm}$ at $\varepsilon=4$. HAGBs fraction increases from $21 \%$ in case at edge region after $\varepsilon=1$ to $82 \%$ after $\varepsilon=4$.

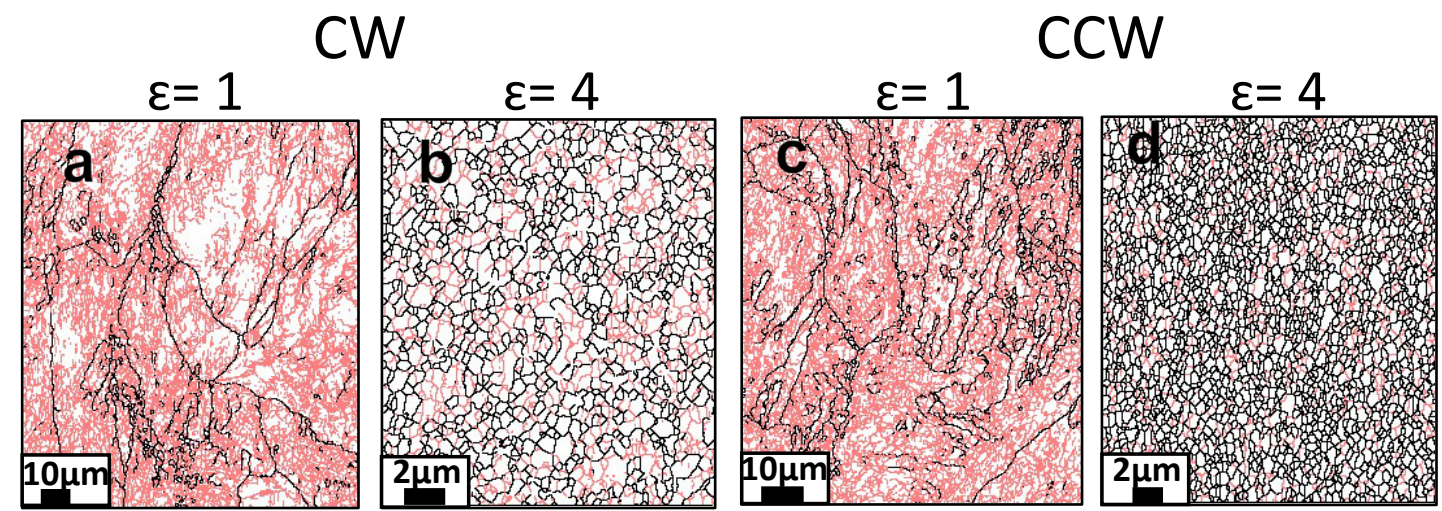

Figure 2. Grain boundary maps of $\mathrm{Al}-2.5 \% \mathrm{Mg}$ clockwise rotations of monotonous deformed specimens $(\mathrm{a} \& \mathrm{~b})$ and strain reversal deformed specimens $(\mathrm{c} \& \mathrm{~d})$.

\section{$\underline{\text { Microtexture Evolution }}$}

The (111) pole figure for the monotonically ((a)-(b)) and strain reversal deformed specimens ((c)-(d)) is shown in Figure 3 and Figure 5 for $2 \mathrm{~N}-\mathrm{Al}$ and $\mathrm{Al}-2.5 \% \mathrm{Mg}$ respectively. Figure 4 and Figure 6 shows the orientation maps depicting the spatial distribution of different texture components for the monotonically ((a)-(b)) and strain reversal deformed specimens ((c)-(d) ) of $2 \mathrm{~N}-\mathrm{Al}$ and $\mathrm{Al}-2.5 \% \mathrm{Mg}$ alloys respectively. The ideal shear texture components are shown in (111) pole figure in Figure (k).

\section{Commercially Pure Aluminium (2N-Al)}

During monotonous deformation, at $\varepsilon=1$ (Figure 3 (a)) a strong presence of the (001)[100] fibre can be observed having a volume fraction of $\sim 18 \%$ (Figure 3 ). Other components are present only in negligible proportion. At $\varepsilon=4$ (Figure $3(\mathrm{~b})$ ), the strong presence of the $\mathrm{C}$ component having a volume fraction of $\sim 15 \%$ along with considerable presence of $\mathrm{A} / \mathrm{A}^{-}$fibre $(\sim 6 \%)$ can be observed (Figure 4$)$.

During strain reversal deformation, at $\varepsilon=1$ (Figure 3 (c)), presence of the $\mathrm{B} / \mathrm{B}^{-}$fibre can be observed with the volume fraction of $\sim 9 \%$ (Figure 4 ). $\mathrm{A}^{*} / \mathrm{A}^{*-}$ fibre is also observed at this strain level with the volume fraction of $\sim 8 \%$. At $\varepsilon=4$ (Figure 3(d)), presence of 
the $\mathrm{A} / \mathrm{A}^{-}$is noticed having the volume fraction of $\sim 9 \%$ (Figure 4). Presence of the $\mathrm{C}$ component is increased to $\sim 6 \%$.

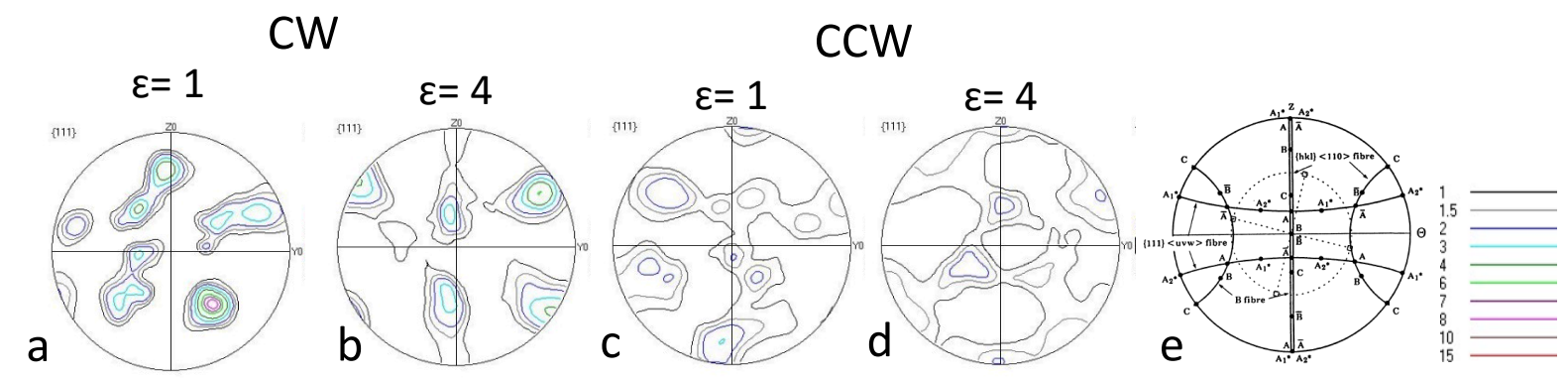

Figure 3. (111) pole figure of $2 \mathrm{~N}-\mathrm{Al}$ for monotonous rotation $(\mathrm{a} \& \mathrm{~b}$ ) and strain reversal (c \& d) at $\mathrm{r} / \mathrm{r}_{0}=1$. The ideal texture components in (111) pole figure (e). [15]

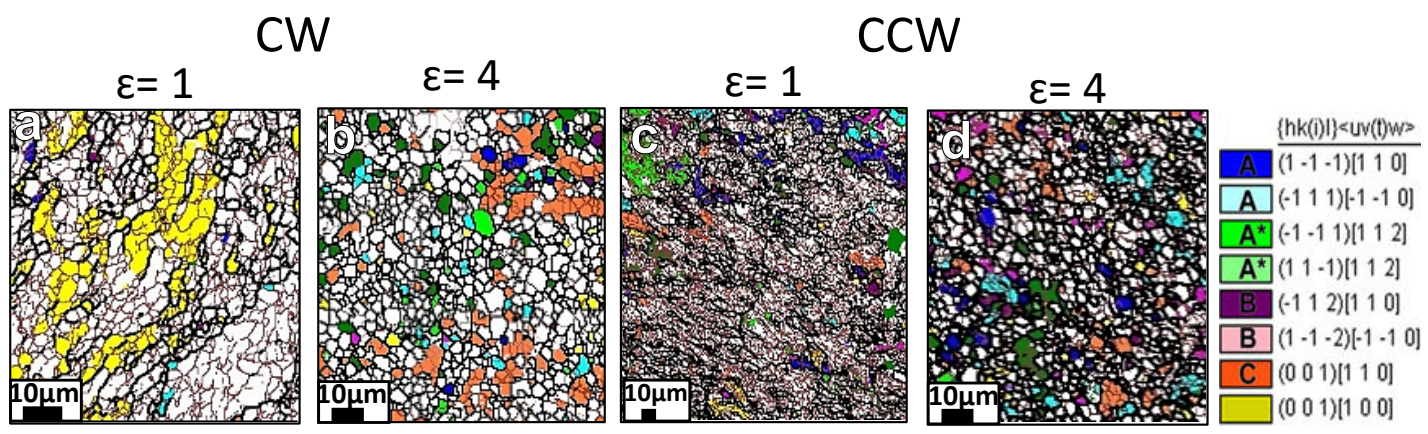

Figure 4. EBSD orientations for $2 \mathrm{~N}-\mathrm{Al}$ for monotonous rotation $(\mathrm{a} \& \mathrm{~b})$ and strain reversal rotations $(\mathrm{c} \& \mathrm{~d})$.

Aluminium Magnesium Alloy $(\mathrm{Al}-2.5 \% \mathrm{Mg})$

During monotonic deformation, at $\varepsilon=1$ (Figure 5 (a), noticeable presence of the $\mathrm{C}$ component can be observed having a volume fraction of $\sim 9 \%$ (Figure 6). Other components are present only in minor proportion and texture appears to be not very strong. The strength of the $\mathrm{C}$ component does not change much following straining to $\varepsilon=4$ (Figure 5 (b)) which is confirmed from the volume fraction of the $\mathrm{C}$ component $(\sim 8 \%)$.

The texture evolution in the strain reversal deformed specimens show characteristic differences with the monotonically deformed specimens. During strain reversal deformation after an imposed strain of $\varepsilon=1$ (Figure $5(\mathrm{c})$ ), the texture appears quite weak such that the volume fraction of the $\mathrm{A}^{*} / \mathrm{A}^{*-}$ component is only $4 \%$. Other components are present even in minor proportions while the volume fraction of the $\mathrm{C}$ component is $\sim 2 \%$ (Figure 6). All the components are strengthened after an imposed strain of $\varepsilon=4$ (Figure 5(d)). The $\mathrm{A}^{*} / \mathrm{A}^{*-}$ component appears relatively stringer having a volume fraction of $\sim 15 \%$ while the volume fraction of $\mathrm{A} / \mathrm{A}^{-}$is found to be $\sim 9 \%$ (Figure 6 ). The fraction of the $\mathrm{C}$ component is almost negligible. 

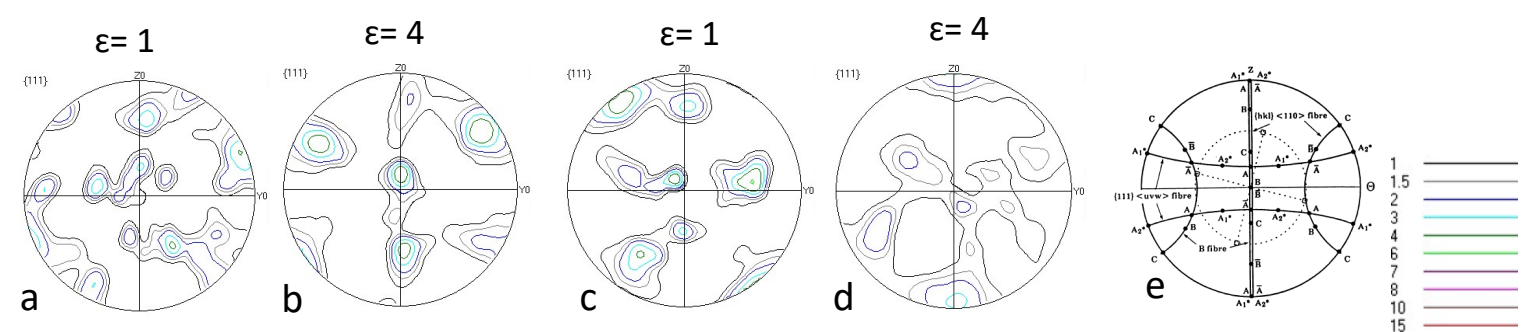

Figure 5. (111) pole figure of the edge regions for Al-2.5\% Mg of monotonically (a \& b) and strain reversal (c \& d) specimens. The ideal texture components in (111) pole figure is shown in (e) [15].

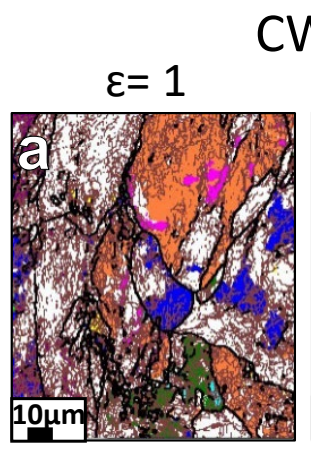

$\mathrm{CW}$

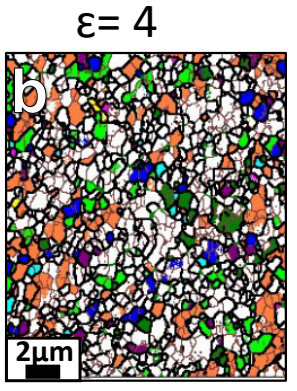

$\mathrm{CCW}$ $\varepsilon=1 \quad \varepsilon=4$

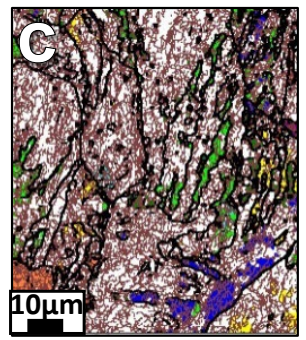

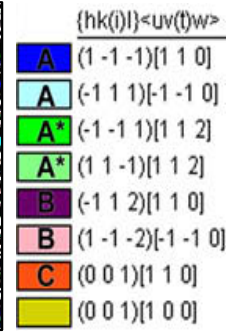

Figure 6. EBSD orientations for Al-2.5\% Mg for monotonous rotation ( $\mathrm{a} \& \mathrm{~b}$ ) and strain reversal rotations $(\mathrm{c} \& \mathrm{~d})$.

\section{Conclusions}

1. The microstructural evolution reveals that the grain refinement for the two deformation modes for the two alloys follows similar trend i.e. initial recrystallized microstructure with large grain size throughout the disk develop prominent LAGBs network inside the grains and ultimately at higher strain i.e. at $\varepsilon=4$ ultrafine equiaxed grains separated by HAGBs throughout the disk evolve. The final grain size of $2 \mathrm{~N}-\mathrm{Al}$ and $\mathrm{Al}-2.5 \% \mathrm{Mg}$ deformed by both deformation modes at higher strain level is observed to be similar. However, lower grain size is observed in case of strain reversal in the two materials.

2. The fraction of HAGBs increases with the imposed strain for the $\mathrm{Al}-2.5 \% \mathrm{Mg}$ alloy in both deformation modes. However the fraction of HAGBs for monotonically deformed is found to be higher than strain reversal deformed $2 \mathrm{~N}$ $\mathrm{Al}$ whereas the trend seems to be opposite in case of $\mathrm{Al}-2.5 \% \mathrm{Mg}$.

3. The evolution of $\mathrm{A} / \mathrm{A}^{-}$and $\mathrm{C}$ components in $2 \mathrm{~N}-\mathrm{Al}$ deformed by the two deformation modes follows similar trend i.e. increasing with increase in strain. However, $\mathrm{A}^{*} / \mathrm{A}^{*}$ - and $\mathrm{B} / \mathrm{B}^{-}$component shows reverse trend. The (001)[100] component is observed at lower strains and a mixed texture is observed to be dominating whereas $\mathrm{C}$ component dominates at $\varepsilon=4$ during monotonic deformation. In strain reversal, a mixed texture but relatively stronger $\mathrm{B} / \mathrm{B}^{-}$ component is observed at lower strains whereas weak texture is observed at higher strain. 
4. In $\mathrm{Al}-2.5 \% \mathrm{Mg}$, similar trend is observed for $\mathrm{A} / \mathrm{A}^{-}, \mathrm{C}$ and $\mathrm{B} / \mathrm{B}^{-}$component for both the deformation modes. A strong $\mathrm{C}$ component is observed at lower strains and a strong $\mathrm{A}^{*} / \mathrm{A}^{*}$ - along with $\mathrm{C}$ component is observed at higher strains for monotonically deformed specimens. During strain reversals, a weak texture is observed at the lower strains and with the increase in the imposed strain, the $\mathrm{A} * / \mathrm{A}^{*}$ - and $\mathrm{A} / \mathrm{A}^{-}$components becomes stronger.

\section{Acknowledgements}

The authors gratefully acknowledge the financial support received from CSIR, India (Grant No. 22(0584)/12/EMR-II), Natural Science and Engineering Research Council (NSERC) and Mitacs. The authors would like to gratefully acknowledge Professor H.S. Kim, POSTECH, South Korea for his kind support for carrying out the HPT processing.

\section{References}

[1] T. Shanmugasundaram et al., "On the Hall-Petch relationship in a nanostructured al-Cu alloy," Materials Science and Engineering A, 527 (2010), 7821-7825.

[2] R.Z. Valiev, R.K. Islamgaliev, I.V. Alexandrov, "Bulk nanostructured materials from severe plastic deformation," Progress in Materials Science, 45(2) (2000), 103 189.

[3] Y. Saito et al., "Novel ultra-high straining process for bulk materials-development of the accumulative roll-bonding (ARB) process," Acta materialia, 47(2) (1999), 579583.

[4] AP. Zhilyaev, T.G. Langdon, "Using high-pressure torsion for metal processing," Fundamentals and applications Progress in Materials Science, 53(6) (2008), 893-979.

[5] M.Kawasaki et al., "The development of hardness homogeneity in pure aluminum and aluminum alloy disks processed by high-pressure torsion." Materials Science and Engineering A, 529 (2011), 345-351.

[6] Cheng Xu, Zenji Horita, Terence G. Langdon, "The evolution of homogeneity in an aluminum alloy processed using high-pressure torsion," Acta Materialia, 56 (10) (2008), 5168-5176.

[7] G.R. Canova, U.F. Kocks, J.J.Jonas, "Theory of torsion texture development," Acta Metall., 32(2) (1984), 211-226.

[8] F.Monthellet, M.Cohen, J.J.Jonas, "Axial stresses and texture development during the torsion testing of Al, Cu and $\alpha-F e, "$ Acta metall., 32 (11) (1984), 2077-2089.

[9] D. Orlov et al., "Texture evolution in pure aluminum subjected to monotonous and reversal straining in high-pressure torsion," Scripta Materialia, 60 (10) (2009), 893896.

[10] Jiuwen Zhang, Nong Gao, Marco J. Starink, "Microstructure development and hardening during high pressure torsion of commercially pure aluminium: Strain reversal experiments and a dislocation based mode," Materials Science and Engineering $A$, 528(6) (2011), 2581-2591.

[11] D.Orlov et al., "Role of strain reversal in grain refinement by severe plastic deformation," Materials Science and Engineering A, 499 (2009), 427-433.

[12] Hyoung Seop Kim, "Finite element analysis of high pressure torsion processing," Journal of Materials Processing Technology, 113 (1-3) (2001), 617-621.

[13] L.S. Toth, J.J.Jonas, D. Daniel, J.A.Bailey, "Texture development and length changes in copper bars subjected to free end torsion," Textures and Microstructures, s19 (1992), 245-262. 